\title{
Modelling Digital Circular Economy framework in the Agricultural Sector. An Application in Southern Italy ${ }^{\dagger}$
}

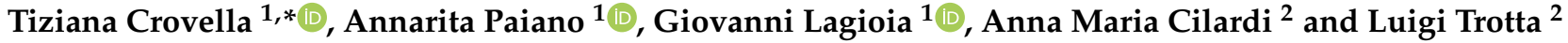 \\ 1 Department of Economics, Management and Business Law (DEMDI), University of Bari Aldo Moro, \\ 70121 Bari, Italy; annarita.paiano@uniba.it (A.P.); giovanni.lagioia@uniba.it (G.L.) \\ 2 Department of Agriculture, Rural and Environmental Development-Section Competitiveness of Agri-Food \\ Chains, Regione Puglia, 70121 Bari, Italy; a.cilardi@regione.puglia.it (A.M.C.); 1.trotta@regione.puglia.it (L.T.) \\ * Correspondence: tiziana.crovella@uniba.it; Tel.: +39-320-01-88148 \\ + Presented at the 13th EFITA International Conference, online, 25-26 May 2021.
}

Citation: Crovella, T.; Paiano, A.; Lagioia, G.; Cilardi, A.M.; Trotta, L. Modelling Digital Circular Economy framework in the Agricultural Sector. An Application in Southern Italy. Eng Proc. 2021, 9, 15. https://doi.org/ 10.3390/engproc2021009015

Academic Editors: Dimitrios Aidonis and Aristotelis Christos Tagarakis

Published: 24 November 2021

Publisher's Note: MDPI stays neutral with regard to jurisdictional claims in published maps and institutional affiliations.

Copyright: (c) 2021 by the authors. Licensee MDPI, Basel, Switzerland. This article is an open access article distributed under the terms and conditions of the Creative Commons Attribution (CC BY) license (https:// creativecommons.org/licenses/by/ $4.0 /)$.

\begin{abstract}
The transition towards circular economy (CE) in agriculture requires a large amount of data in order to map the consumption of natural resources and negative externalities. This paper aims to identify a digital framework for collecting and sharing data fundamental for stakeholders with the purpose of implementing the best CE model. The methodology used is based on the guidelines of the stakeholder engagement and through a survey, and the authors have mapped the lack of data and built a set by replicable sustainability indicators. The results obtained can be used for the definition of regional policy strategies and interventions for CE model implementation.
\end{abstract}

Keywords: agriculture; circular economy; survey; data; indicators; digital framework

\section{Introduction}

Digital transformation plays a fundamental role in all economic sectors, especially in agriculture [1]. For this reason, currently, the paradigm of data collection needs to be improved, as suggested by [2], in order to present a systematic model to enable stakeholders to transition towards CE.

\section{Literature Review}

The scientific interest in the fundamental digital transformation to implement the $\mathrm{CE}$ in agriculture is fairly recent, as the Web of Science (WoS) platform highlighted only two a few results. According to [2], the correct coordination between computer devices and agriculture can contribute to improvement in the management of farms and their practices. In 2019, other scholars [3] stated that a long-term agricultural data collection model ensured comprehensive monitoring of sustainable agriculture and the design of development plans. Given the shortage of this significant practice [4], we proposed this study in order to increase the scientific production and suggest a new framework for implementing $C E$ in agriculture.

\section{Materials and Methods}

\subsection{Methods}

The methodology used is defined by the guidelines on stakeholder engagement (AA1000 SES) issued by [5] and based on three key items: 1. involving stakeholders to understand their expectations on governance, policies, strategies, and practices; 2. reporting of data and questions in accordance with transparency and clarity; 3 . developing an innovative framework to address the sustainability issue. 


\subsection{Materials}

The stakeholder engagement methodology is based on questionnaire administration to understand the needs identified by stakeholders and farmers during planning and managing project activities concerning the sustainability and circular economy issue. Data gathered through the questionnaire were processed and transformed through a statistical tool into a shareable framework.

\subsubsection{Questionnaire}

We developed a questionnaire jointly for with public administration for mapping the needs of stakeholders in terms of information and knowledge to implement CE. Table 1 displays the 21 questions, which are categorized into four areas of investigation.

Table 1. Structure of questionnaire.

\begin{tabular}{|c|c|c|}
\hline Area & Questions & $n$. \\
\hline General & $\begin{array}{l}\text { Professional area } \\
\text { General difficulties for farmers to implement CE } \\
\text { Information for implementing SA }\end{array}$ & $1-3$ \\
\hline Circular Economy & $\begin{array}{l}\text { CE practices in Apulia } \\
\text { Farmers' interest in CE } \\
\text { CE model in Apulian agriculture } \\
\text { Obstacles in CE implementation } \\
\text { Range of problems } \\
\text { Fundamental keys for CE implementation } \\
\text { Effective processes } \\
\text { Sustainability indicators }\end{array}$ & $4-11$ \\
\hline Water Resource & $\begin{array}{l}\text { Wastewater reuse in Apulian agriculture } \\
\text { Practices of wastewater reuse } \\
\text { Spreading olive oil mill wastewater (OOMW) } \\
\text { Information of Regional Water Protection Plan } \\
\text { Instruments and tools for improving CE of water resource }\end{array}$ & $12-16$ \\
\hline Planning & $\begin{array}{l}\text { Relevant topic for planning and financing calls } \\
\text { Digital data and information } \\
\text { Collaboration for designing digital framework } \\
\text { Advice } \\
\text { Sharing results }\end{array}$ & $17-21$ \\
\hline
\end{tabular}

\subsubsection{Sample}

Jointly with a regional body, we made a list of stakeholders involved in the survey. The sample was composed of 32 stakeholders from different areas that operate in private associations, public authorities, research centers, and regional agencies connected with the Apulian agricultural sector. The questionnaire was shared through a digital platform.

\section{Results}

Concerning question 2, half of the answers showed an absence of direct channels of information for CE in the Apulian agricultural sector and $40 \%$ complained of the lack of technical training. Two thirds of the answers for question 3 stated that Apulian farmers require information about sustainable use of natural resources. Additionally, according to $75 \%$ of the sample investigated, in the Apulian agriculture sector, some models of CE have been activated anyway. Thirty-three percent of these stakeholders were contacted about wastewater reuse in the past. All stakeholders agreed that regional farmers face difficulties in implementing an appropriate and useful model of CE, mostly $(67 \%)$ due to a lack of information and specific training. According to our stakeholder sample, sustainable water use will be an important key to implement $C E$ in Apulia, and wastewater reuse and food waste reuse followed. Notwithstanding the successful framework to implement $\mathrm{CE}$ will 
be the adoption of participatory processes between stakeholders and farmers. In terms of sustainable indicators, $67 \%$ of the sample were aware of them, whereas, according to $16 \%$ of the stakeholders, in the Apulian agriculture sector, wastewater reuse based on rainwater storage is widespread. Thirty-three percent of the sample has already had to deal with farmers who practised an agronomic use of vegetation waters. Unfortunately, no farmers know the Regional Water Protection Plan. Fifty-eight percent of the sample focused on the need for coordination between the different implementing bodies. Additionally, for planning and financing activities, the management of digital information and the use of a connected network will be fundamental. Currently, according to $92 \%$ of the sample, Apulian farmers have difficulties in retrieving collected and digital information in the short term. Nevertheless, $67 \%$ of the sample is available to collaborate for planning a participatory model for collected information useful for implementing CE in Apulia. It has to be underlined that all stakeholders agreed to share the results of this survey.

Finally, in the last step of this study, we developed some indicators for making a framework useful for all stakeholders involved in the agri-food chain (from farmers to public and private bodies) for implementing a successful CE model in agriculture. Figure 1 displays a replicable framework organized into the eight most important topics that are interconnected and fundamental to meet the needs highlighted by our sample.

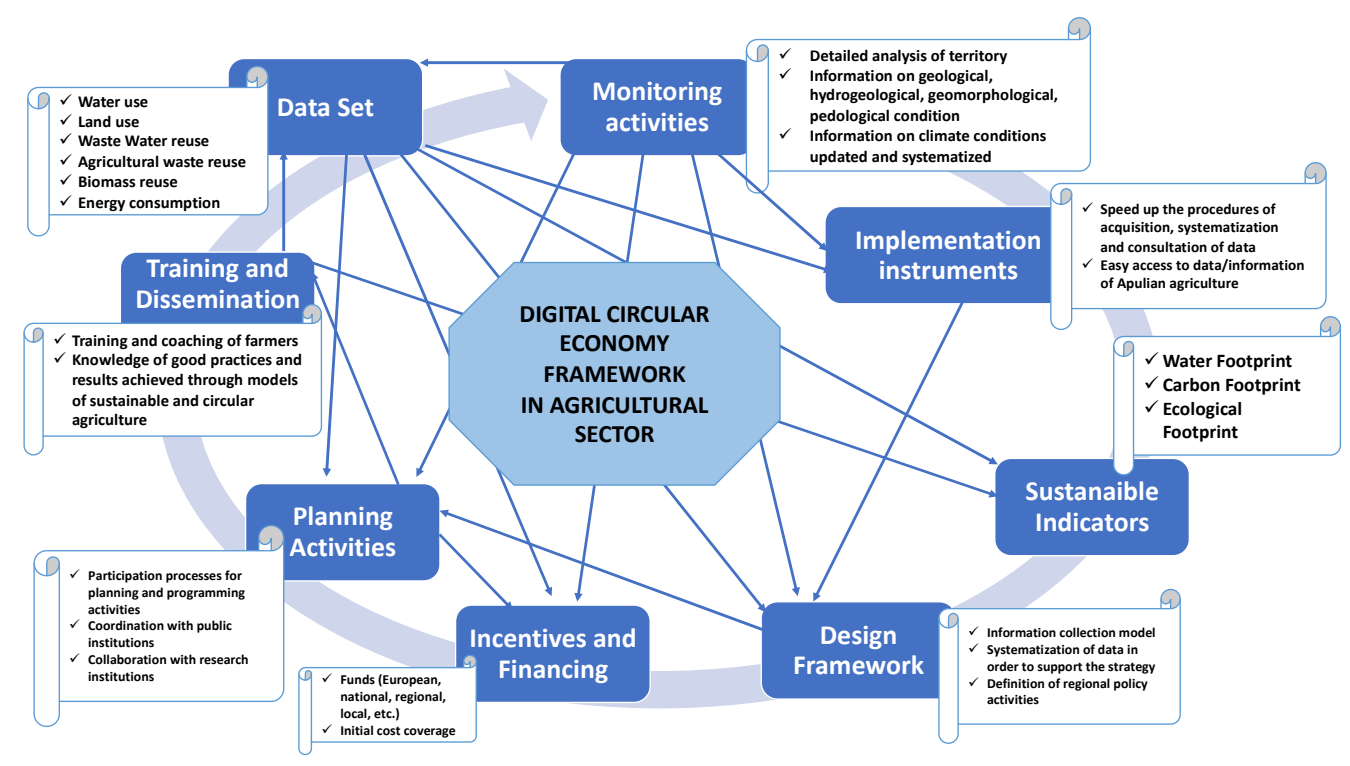

Figure 1. Framework for implementing a CE model in agriculture. Source: Authors' own work.

\section{Discussion}

This paper deals with some useful insights from the scientific literature in order to create a digital framework for data collection and sharing in agriculture. Furthermore, this analysis feeds responsible innovation processes for a correct transition from the linear economy to circular economy [1]. The investigation, undertaken through the use of digital tools, encompassed the consumption of natural resources, such as water resources, and the knowledge of some sustainability indicators and limitations to implementing CE in agriculture. This information is significant for planning activities, creating financing policies, and enabling the implementation of tools for Apulian agriculture. Therefore, based on the first questionnaire administered to the sample (public and private bodies and associations of agriculture), the need to conduct training and dissemination activities based on bottom-up and top-down approaches emerged. The key element for the transition to the $\mathrm{CE}$ is represented by the collaboration between farmers and stakeholders to design agricultural management based on a digital model of data, information, and knowledge. 


\title{
6. Conclusions
}

We proposed this framework based on a dynamic and interdependent relationship between several fundamental steps to design a transition towards a CE approach. This digital framework improves stakeholders' decision making [6] and leads to greater cooperation in the agricultural supply chain in Southern Italy and in the Mediterranean area. It is a knowledge model that allows for overcoming the obstacles that the stakeholders of the agricultural supply chain face in the data procurement phase [7]. Furthermore, since this is the building of a replicable framework, it allows the spread of soft culture and digital learning, creating a virtuous network to be implemented in the Mediterranean area. We have thus strengthened the capacity of public administrations by combining scientific research and public/private interests for the implementation of the circular economy approach. Therefore, this new framework can spin public administration to design plans, strategies, and programs and enable stakeholders to know the most suitable sustainability indicators to implement the best $\mathrm{CE}$ model. In conclusion, digital transformation in agriculture supports a framework of digital-enabled circular strategies for farms and manufacturing.

\begin{abstract}
Author Contributions: Conceptualization, T.C. and A.P.; methodology, T.C. and A.P.; software, T.C.; validation, A.M.C. and L.T.; formal analysis, T.C. and A.P.; investigation, T.C.; resources, A.M.C.; data curation, T.C.; writing — original draft preparation, T.C. and A.P.; writing—review, G.L., writing — editing, T.C.; visualization, T.C.; supervision, G.L. and L.T.; project administration, G.L. All authors have read and agreed to the published version of the manuscript.
\end{abstract}

Acknowledgments: This research was undertaken thanks to a partnership between the University of Bari Aldo Moro (Department of Economics, Management and Business Law), Regione Puglia (Department of Agriculture, Rural Development and Environmental), and ADISU Puglia for the MoDEC Apulia Programme 13/16.

Conflicts of Interest: The authors declare no conflict of interest.

\section{References}

1. Lajoie-O'Malley, A.; Bronson, K.; van der Burg, S.; Klerkx, L. The future(s) of digital agriculture and sustainable food system: An analysis of high-level policy documents. Ecosyst. Serv. 2020, 45, 101183. [CrossRef]

2. Chehri, A.; Chaibi, H.; Saadane, R.; Hakem, N.; Wahbi, M. A framework of optimizing the development of IoT for precision agriculture industry. 24th International Conference of Knowledge-Based and Intelligent Information \& Engineering Systems. Proc. Comp. Sci. 2020, 176, 2414-2422. [CrossRef]

3. Della Chiesa, S.; la Cecilia, D.; Genova, G.; Balotti, A.; Thalheimer, M.; Tappeiner, U.; Niedrist, G. Farmers as data sources: Cooperative framework for mapping soil properties for permanent crops in South Tyrol (Northern Italy). Geoderma 2019, 342, 93-105. [CrossRef]

4. Klerkx, L.; Jakku, E.; Labarthe, P. A review of social science on digital agriculture, smart farming and agriculture 4.0: New contributions and a future research agenda. Wagening. J. Life Sci. 2019, 90, 100315. [CrossRef]

5. AccountAbility. Stakeholder Engagement Standard (AA1000SES). Available online: https://www.accountability.org/standards/ (accessed on 10 January 2021).

6. Newton, J.E.; Nettle, R.; Pryce, J.E. Farming smarter with big data: Insights from the case of Australia's national dairy herd milk recording scheme. Agric. Syst. 2020, 181, 102811. [CrossRef]

7. Wolfert, S.; Ge, L.; Verdouwa, C.; Bogaardt, M.J. Big Data in Smart Farming-A review. Agric. Syst. 2017, 153, 69-80. [CrossRef] 